\title{
Gemcitabine followed by radiotherapy in treatment of newly diagnosed high-grade gliomas
}

\author{
Maha El-Naggar ${ }^{1,3}$, Mervat Omar ${ }^{1}$, Ahmed Elgeriany², Godefridus J. Peters ${ }^{3}$, Amina Mostafa ${ }^{1}$, Samir Shehata ${ }^{1}$ \\ ${ }^{\prime}$ Department of Medical oncology, Assiut University Hospital, Assiut 71515, Egypt. \\ ${ }^{2}$ Department of Neurosurgery, Assiut University Hospital, Assiut 71515, Egypt. \\ ${ }^{3}$ Department of Medical Oncology, VU University Medical Center, 1081 HV Amsterdam, the Netherlands.
}

Correspondence to: Dr. Maha El-Naggar, Department of Medical oncology, Assiut University Hospital, Assiut 71515, Egypt. E-mail: maha_elnaggar@yahoo.com

\begin{abstract}
A B S T R A C T
Aim: High-grade glioblastoma multiforme (GBM) has a poor median overall survival (OS). The standard treatment after surgery is temozolomide and radiotherapy (RTH). Patients with unmethylated methylguanine-methyltransferase promoter (MGMT) have no or little benefit from temozolomide and are eligible for alternative therapies. Gemcitabine is a good radiosensitizer. We aimed to evaluate the combination of gemcitabine with RTH in newly diagnosed GBM. Methods: The study was a prospective phase II study. Eligible patients were required to have histologically proven anaplastic astrocytoma or GBM. Patients underwent biopsies or subtotal resection. The treatment consisted of fixed-dose rate gemcitabine $175 \mathrm{mg} / \mathrm{m}^{2}$ weekly followed after $24 \mathrm{~h}$ by standard cranial RTH for 6 weeks. Tumor response was evaluated by Macdonald criteria. In case of progression, patients received temozolomide (200 mg/m²/5 days every 28 days). Results: Thirty patients with a median age of 52 years (30-69), 73\%/27\% male/female, the Eastern Cooperative Oncology Group performance status 1 (range 0-2) were enrolled. Five patients had a partial-response (17\%) and 13 stable-disease (43\%). Median time to progression was 7.88 months (95\% CI 6.1-9.69) and OS was 11.77 months (95\% CI 9.97-13.56). The treatment was well tolerated with grade-3 neutropenia in 3, grade-3 anemia in 2 and impaired liver enzymes in 1 patient. Conclusion: Gemcitabine followed by radiotherapy is active and promising regimen in newly diagnosed GBM. Gemcitabine uptake is easy, with a long local retention of active metabolites, precluding systemic side effects of radiosensitization. In a phase III study this treatment should be evaluated in patients with unmethylated MGMT promoter who will not benefit from temozolomide.
\end{abstract}

Key words: Gemcitabine; radiation; glioblastoma multiforma; temozolomide

\section{INTRODUCTION}

Malignant gliomas grade 3 anaplastic astrocytoma (AA) or grade 4 glioblastoma multiforme (GBM) are rapidly progressing primary brain tumors, which in spite of advances in surgery, radiotherapy and chemotherapy, remain associated with high morbidity and mortality. ${ }^{[1]}$ Despite the current multimodality therapy, the overall median survival for newly diagnosed patients is 10 months for patients with GBM and 2-3 years for those with AA. ${ }^{[2,3]}$

Standard treatment of malignant gliomas is surgery, followed by radiotherapy concomitant with temozolomide (TMZ), followed by adjuvant TMZ (Stupp et al., ${ }^{[2]} 2005$ ). Surgery followed by involved field radiotherapy up to total

\begin{tabular}{|l|l|}
\hline \multicolumn{3}{|c|}{ Access this article online } \\
\hline Quick Response Code: & Website: \\
& http://jcmtjournal.com \\
\cline { 2 - 2 } & \\
\hline
\end{tabular}

dose of 60 Gray (Gy) significantly prolongs survival. There have been many efforts to intensify radiotherapy, including the use of radiosenstizers, brachytherapy, radioactive seeds implanted in the tumor bed, and stereotactic radiosurgery in selected cases. ${ }^{[4]}$

Initially the routine use of chemotherapy in addition to cranial irradiation was controversial. Individual randomized, controlled studies demonstrated no significant improvement in median survival with single agent or multiple agents chemotherapy, although a significant increase in survival was noted in a meta-analysis. ${ }^{[1]}$ There was a significant

This is an open access article distributed under the terms of the Creative Commons Attribution-NonCommercial-ShareAlike 3.0 License, which allows others to remix, tweak, and build upon the work non-commercially, as long as the author is credited and the new creations are licensed under the identical terms.

For reprints contact: service@oaepublish.com

\footnotetext{
How to cite this article: El-Naggar M, Omar M, Elgeriany A, Peters GJ, Mostafa A, Shehata S. Gemcitabine followed by radiotherapy in treatment of newly diagnosed high-grade gliomas. J Cancer Metasta Treat 2016;2:188-94

Received: 05-04-2016; Accepted: 09-05-2016.
} 
increase in the proportion of long-term survivors with the addition of chemotherapy, from less than 5 percent to approximately 15-20 percent, regardless of the patient's performance status, the histological features of the tumor, the duration of symptoms or age (up to 65 years). ${ }^{[5]}$

However, the combination of radiotherapy with TMZ completely changed standard therapy, since this improved the median survival and overall survival. ${ }^{[2]}$ However, not all patients benefit since an unmethylated promoter of methylguanine methyltransferase (MGMT) enables extensive repair of TMZ-adducts and these patients do not benefit from temozolomide ${ }^{[6]}$ and are eligible for development of alternative therapies. Moreover, TMZ is relatively a poor radiosensitizer compared with other cytotoxic drugs ${ }^{[7]}$ However, the group of nucleoside analogs, including gemcitabine are excellent radiosensitizers. ${ }^{[8,9]}$ Gemcitabine has been evaluated as a radiosensitizer for several tumor types, both in model systems and patients. ${ }^{[8,10]}$ Gemcitabine, an analogue of deoxycytidine, enters the cell by the action of a nucleoside transporter ${ }^{[11]}$ and it is activated by phosphorylation in a reaction catalyzed by deoxycytidine kinase (DCK), to gemcitabine monophosphate (dFdCMP) and subsequently phosphorylated to the 5'-diphosphate (dFdCDP) and triphosphate (dFdCTP) derivatives. ${ }^{[12,13]}$ Gemcitabine exerts its cytotoxicity mainly through the irreversible incorporation of the activated triphosphate into DNA, resulting in chain termination. Due to a number of self-potentiating mechanisms, gemcitabine exhibits prolonged intracellular retention, a property likely partially responsible for gemcitabine's broad spectrum of activity. ${ }^{[14,15]}$

The standard dose of gemcitabine $\left(1,000 \mathrm{mg} / \mathrm{m}^{2}\right)$ given over $30 \mathrm{~min}$ results in high gemcitabine peak levels (> $20 \mu \mathrm{mol} / \mathrm{L}$ ), which rapidly decline below $1 \mu \mathrm{mol} / \mathrm{L}$ within $2 \mathrm{~h} \cdot{ }^{[16,17]}$ However, DCK is saturated at much lower gemcitabine levels and in vitro and in vivo sensitivity to gemcitabine is most optimal at prolonged exposure to low drug levels in the nanomolar range. ${ }^{[18-20]}$ Therefore, it was reasoned that prolonged infusion of gemcitabine, which would result in prolonged but lower plasma concentrations of gemcitabine, would be advantageous. ${ }^{[16,21]}$ The fixed dose rate of $10 \mathrm{mg} / \mathrm{m}^{2} / \mathrm{min}$ infusion of gemcitabine gives this pharmacodynamic advantage over the 30 min infusion, ${ }^{[16]}$ resulting in a prolonged formation and retention of gemcitabine nucleotides which favour the activity of gemcitabine. A phase II trial showed that fixed dose rate gemcitabine can improve survival in patients with pancreatic adenocarcinoma but the difference was not significant in a randomized study. ${ }^{[22]}$ Single agent studies of gemcitabine in high grade glioma did not show any benefit, ${ }^{[23,24]}$ so that development of gemcitabine for this disease was discontinued. However, gemcitabine has shown a radiosensitizing effect in a number of human glioma cell lines ${ }^{[25-27]}$ and in an animal model system. ${ }^{[28]}$
Sigmond et al. ${ }^{[29]}$ demonstrated that gemcitabine could pass the blood-tumor barrier in GBM patients. In tumor samples, concentrations of gemcitabine and its active metabolite dF-dCTP were high enough to enable radio sensitization, which warrants clinical studies using gemcitabine in combination with radiation.

Weller et al. ${ }^{[24]}$ and Metro et al. ${ }^{[30]}$ indeed showed that gemcitabine combined with RTH was an active regimen, but whether it was more effective than RTH alone remained elusive. The combination gemcitabine-RTH followed by temozolomide showed promising activity. ${ }^{[30]}$ Preliminary results of another phase I study showed that gemcitabine combined with radiotherapy is efficient and tolerable in high grade glioma. ${ }^{[31]}$ The aim of our study was to evaluate the activity of gemcitabine with RTH as a treatment modality in newly diagnosed high- grade gliomas and temozolomide was administered after progression only.

\section{METHODS}

This was single center, phase II, open label, one arm non-randomized trial designed to determine the efficacy and safety of gemcitabine combined with therapy in the treatment of patients with newly diagnosed malignant glioma. The Research Ethics Board of Assiut University Hospital approved the study. All patients gave written informed consent before starting treatment.

\section{Patients}

Eligible patients had histologically proven malignant glioma (grade 3 or 4). Patients were at least 18 years of age; had the Eastern Cooperative Oncology Group (ECOG) performance status $<3$, had adequate bone marrow reserves (hemoglobin $>9 \mathrm{~g} / \mathrm{dL}$, absolute granulocytes $>1.5 \times 10^{9} / \mathrm{L}$, platelets $\left.>100 \times 10^{9} / \mathrm{L}\right)$, and acceptable serum chemistries (serum calcium in normal range $(8.8-10.2 \mathrm{mg} / \mathrm{dL})$, serum creatinine $<1.5 \times$ upper limit of normal, bilirubin $<1.5 \times$ upper limits of normal and AST (aspartate transaminase) $<$ $3 \times$ upper limits of normal).

Patients were excluded if they were $<18$ years old, had previous invasive malignancies or received previous chemotherapy or radiotherapy, had poor medical conditions, or were pregnant, nursing or not practicing effective contraception if appropriate.

\section{Assessments and treatment plan}

Pre-treatment evaluation included a history and physical and neurological examination, laboratory (complete blood picture, liver and kidney function, serum calcium level) and imaging studies (baseline CT and MRI brain) and a baseline toxicity evaluation.

After surgery of patients with malignant gliomas for either cytoreduction or a biopsy, patients received fractionated local RTH at a daily dose of 2 Gray (GY) per fraction, five days per week for six weeks (total dose of $60 \mathrm{GY}$ ). 
RTH was applied to the gross tumor volume with $2-3 \mathrm{~cm}$ margin for the clinical target volume. Radiotherapy was carried out using linear accelerator with 6-15 MV photons. Gemcitabine was administered at a fixed dose of $175 \mathrm{mg} / \mathrm{m}^{2}$ by intravenous infusion starting $24 \mathrm{~h}$ prior to radiotherapy in the first week and then once weekly before RTH for the whole duration of the radiotherapy. Toxicities were graded using the NCIC-CTG expanded common toxicity criteria. Evaluation during protocol treatment included history and physical examinations (including full clinical neurologic examination), biochemical profiles; and imaging studies. Contrast-enhanced (gadolinium-DTPA) MRI of the brain was uniformly adopted for tumor assessment and evaluation of response. Baseline MRI examination was performed 24-48 $\mathrm{h}$ after surgery and then within 1 week prior to the start of the experimental treatment, 4 weeks after the end of chemo-radiotherapy and every 8 weeks thereafter until evidence of disease progression. Toxicity assessments were done weekly during the radiotherapy and then one month from the end of the treatment then every 2 months or when clinically indicated. Toxicity was graded according to NCICTC version 3.0. ${ }^{[32]}$ Response was assessed using standard Macdonald criteria, ${ }^{[33]}$ but patients were not considered to have had complete or partial responses unless clinical neurologic assessment was improved or stable. Patients were monitored until death.

\section{Statistics}

The duration of response was calculated from the first day of treatment to the date of progression for patients who achieved complete or partial response. Progression-free survival, analyzed by Kaplan-Meier method including 95\% $\mathrm{CI}$, was defined as the period of time elapsed from the first day of treatment to the date of disease progression, relapse or death from any cause. Overall survival was defined as the interval from the first day of study treatment to the date of patient death. The survival curves were estimated by the Kaplan-Meier product-limit method. The SPSS (11.0) statistical program was used for analysis.

\section{RESULTS}

\section{Patients}

From April 2009 to April 2011, thirty patients were enrolled. Table 1 shows the characteristics of patients entered on the study. Of the 30 patients included in the analyses, 8 were female and 22 male, with a median age of 52 years (range 30-69). Patients had an ECOG performance status range 0 to 2 . There were 8 patients with anaplastic astrocytoma, and 22 with glioblastoma multiform.

\section{Outcome}

All patients received concomitant dexamethasone, while anti-convulsant treatment was given on demand. All the patients completed the chemoradiotherapy treatment. Six patients responded to the treatment $(20 \%)$ and 13 patients had stable disease $(43 \%)$ for an overall disease control rate
Table 1: Patient characteristics

\begin{tabular}{lc}
\hline Total patients & 30 \\
\hline Age in years, median (range) & $52(30-69)$ \\
Gender & \\
Male & $22(73 \%)$ \\
Female & $8(27 \%)$ \\
ECOG performance status, & $1(0-2)$ \\
median (range) & \\
Pathology & $8(27 \%)$ \\
Anaplastic Astrocytoma & $22(73 \%)$ \\
Glioblastoma multiforma & \\
Surgical procedure & $10(33 \%)$ \\
Subtotal resection & $20(67 \%)$ \\
Biopsy &
\end{tabular}

ECOG: Eastern Cooperative Oncology Group

Table 2: Treatment response

\begin{tabular}{lc}
\hline Response & Patient number (\%) \\
\hline Complete response (CR) & $1(3)$ \\
Partial response (PR) & $5(17)$ \\
Stable disease (SD) & $13(43)$ \\
Progressive disease (PD) & $11(37)$ \\
Disease control rate (CR+PR+SD) & $19 / 30(63)$ \\
Tumor response rate (CR+PR) & $6 / 30(20)$ \\
\hline
\end{tabular}

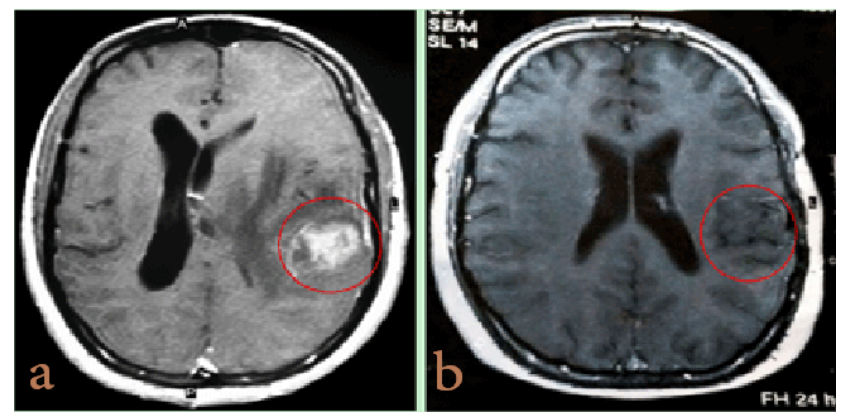

Figure 1: (a) MRI in T1 after Gd-DTPA infusion in axial plane shows an area of enhancement in GBM in the left parietal area; (b) MRI performed 1 year after the end of chemo-radiotherapy shows a dramatic response of the tumour T1 axial plane after Gd-DTPA infusion. MRI: magnetic resonance imaging; GBM: glioblastoma multiforme
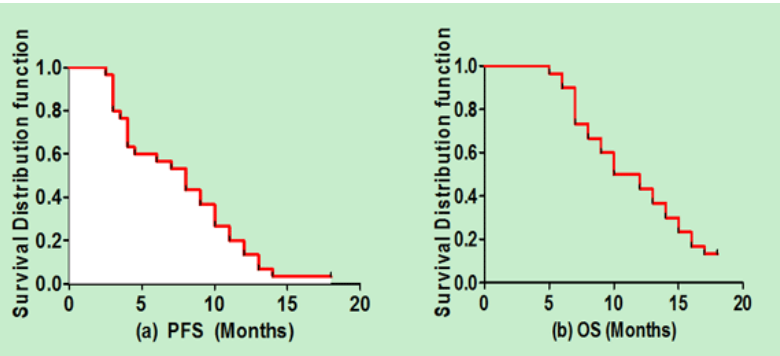

Figure 2: (a) PFS at a follow up of 18 months. The median PFS was 7.9 months (95\% Cl 6.1-9.7); (b) analysis of OS for 18 months, median OS was 11.8 months $(95 \% \mathrm{Cl} 10.0-13.6)$. PFS: progression free survival; OS: overall survival

of $63 \%$ [Table 2] [Figures 1 and 2]. At a median follow up of 18 months median time to progression was 7.88 months (95\% CI 6.1-9.69) and overall survival was 11.77 months (95\% CI 9.97-13.56). According to the histology Grade 3 


\begin{tabular}{lllll}
\hline & $\begin{array}{l}\text { Grade 1 } \\
\text { Patient number } \\
(\%)\end{array}$ & $\begin{array}{l}\text { Grade 2 } \\
\text { Patient number } \\
(\%)\end{array}$ & $\begin{array}{l}\text { Grade 3 } \\
\text { Patient number } \\
(\%)\end{array}$ & $\begin{array}{l}\text { Grade 4 } \\
\text { Patient number } \\
(\%)\end{array}$ \\
\hline Heamatological toxicity & $2(7)$ & $2(7)$ & $3(10)$ & 0 \\
Neutropenia & $2(7)$ & $1(3)$ & $2(7)$ & 0 \\
Aneamia & $1(3)$ & 0 & 0 & 0 \\
Thrombocytopenia & $2(7)$ & $1(3)$ & $1(3)$ & 0 \\
Non heamatological toxicity & $2(7)$ & 0 & 0 & 0 \\
Impaired liver enzymes & $3(10)$ & $1(3)$ & 0 & 0 \\
Fever & $2(7)$ & $1(3)$ & 0 & 0 \\
Nausea/vomiting & $2(7)$ & $2(7)$ & 0 & 0 \\
Anorexia & $3(10)$ & 0 & 0 & 0 \\
Diarrhea & $2(7)$ & 0 & 0 & 0 \\
Fatigue & $4(13)$ & 0 & 0 & 0 \\
Convulsion & $1(3)$ & $4(13)$ & 0 & 0 \\
Headache & $9(30)$ & 0 & 0 & 0 \\
Insomnia & $1(3)$ & 0 & 0 & 0 \\
Alopecia & $2(7)$ & & & 0 \\
Otitis externa & & 0 & \\
Scalp dermatitis & & & 0 \\
\hline
\end{tabular}
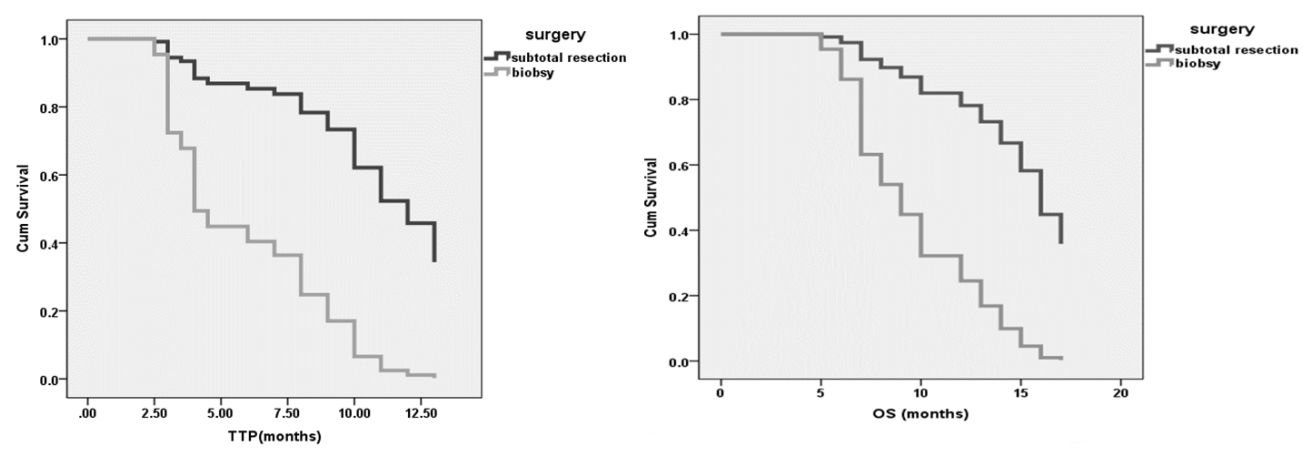

Figure 3: Subgroup analysis of PFS (depicted as Time to Progression, TTP) and OS according to surgical extension median PFS of 11 months (95\% CI 8.1 13.9) for subtotal resection versus 4 months $(95 \% \mathrm{Cl} 3.5-4.6)$ for a biopsied patients and median OS 15.4 months (95\% $\mathrm{Cl} 13.5-17.3)$ versus 9.5 months $(95 \%$ $\mathrm{Cl}$ 8.1-11.0) for subtotal resection versus biopsy, respectively. PFS: progression free survival; OS: overall survival

astrocytoma has more favorable PFS 11.13 months $(95 \%$ CI 9.37-12.88) and OS 15.25 months (95\% CI 12.5417.96) than Glioblastoma multiform patients with PFS 6.70 months (95\% CI 4.505-8.90) and OS 10.50 months (95\% CI 8.41-12.59). On multivariate analysis, factors predictive of progression were performance status $(P$ $=0.04)$ and the extent of surgery $(P=0.02)$. The latter was evaluated in a subgroup analysis, which showed that patients with a subtotal resection had a higher probability for a longer survival than those patients who were only biopsied [Figure 3].

\section{Safety}

All patients completed radiotherapy for a total dose of $60 \mathrm{~Gy}$. All patients were evaluable for safety of the combination of gemcitabine and radiotherapy. Treatment-related adverse events are summarized in Table 3. Generally the treatment was well tolerated. Hematological toxicity consisted of grade 3 neutropenia in three patients $(10 \%)$, while grade 3 anemia was reported in 2 patients $(7 \%)$ on day 24 ; these patients received packed red blood cells. In the 3 cases of neutropenia, this was afebrile and occurred on day 16 in 2 cases and on day 24 in one case after the initiation of study treatment. Also, non-hematological adverse events were mostly mild (grade 1) or moderate (grade 2) in intensity. Hypertransaminasemia was the only grade 3 non-hematological adverse event in one patient $(3 \%)$, and this patient was receiving antiepileptic treatment. No treatment-related grade 4 toxicities were observed.

\section{DISCUSSION}

In this study we demonstrated that gemcitabine followed by RTH is an active regimen for treatment of high grade newly diagnosed GBM. Our study met the primary activity objective, producing a response rate of $20 \%$ and disease control rate of $63 \%$, which was in line with earlier gemcitabine/RTH data of $17.5 \%$ and $75 \%$, respectively. ${ }^{[30]}$ The results of these gemcitabine/RTH studies compare favorably with corresponding values for activity and disease control of $15.5 \%$ and $57.5 \%$, respectively, obtained with nitrosurea given concurrently with radiotherapy. ${ }^{[34]}$ Furthermore, the promising values of PFS of 7.88 months and OS 11.77 months are in the same range as that observed for temozolomide plus radiotherapy 6.9 months for PFS and of 14.6 months for OS. ${ }^{[2]}$

However, it is difficult to compare PFS and OS of the present study with those obtained in studies of radiotherapytemozolomide with or without adjuvant temozolomide, 
where $17.5-34.5 \%$ of patients had received complete tumor resection prior to study entry. ${ }^{[2,35]}$ All patients in our study had residual disease after surgery, while $67 \%$ of the patients were biopsied-only. A subgroup analysis of TMZ plus radiotherapy showed that the 93 patients who underwent only biopsy had no significant improvement in median overall survival. ${ }^{[2]}$

Although PFS was the secondary objective in the present study, our results are not likely to be influenced by sequential temozolomide as it was only given after progression of the patients. In contrast, OS may be affected by the TMZ administered at disease progression. In another study, ${ }^{[30]}$ this might not have been the case.

The combination of gemcitabine plus radiotherapy was well tolerated. No treatment-related grade 4 toxicities were observed, while there were only 6 cases of grade 3 adverse events, including 5 patients with hematological toxicity and one with hypertransaminasemia .This was in line with toxicity reported for gemcitabine with RTH in high grade glioma patients with weekly schedule. ${ }^{[30]}$ On the whole, the treatment-related morbidity did not differ significantly from that observed with nitrosourea or temozolomide given concurrently with radiotherapy. ${ }^{[2,34,35]}$

The standard treatment of high grade glioma patients has changed considerably since the introduction of radiotherapy combined with temozolomide. ${ }^{[2,36]}$ However, the benefit is only achieved in a subgroup of patients, who have a methylated MGMT promoter in the tumor. ${ }^{[6]}$ The patients with a hypomethylated MGMT promoter have an active MGMT enzyme, which will repair the DNA damage. Moreover, even in cells with a methylated MGMT promoter TMZ is a relatively poor radiosensitizer. ${ }^{[7]}$ Therefore these patients are eligible for an alternative treatment. Although gemcitabine as a single drug does not have an antitumor activity against $\mathrm{GBM}^{,[2,24]}$ this is not due to a poor passage of the blood-brain barrier. Normal brain depends on preformed nucleosides to enable nucleotide synthesis in the brain. ${ }^{[37]}$ Since gemcitabine resembles normal deoxynucleosides it is not unexpected that it is taken up efficiently into the brain and that the blood-brain barrier does not preclude gemcitabine's passage. ${ }^{[29]}$ Although the low dose of gemcitabine would preclude an antitumor effect by the drug itself, this dose results in sufficiently high concentrations in the tumor for radiosensitization can be reached. Since gemcitabine is an excellent radiosensitizer, low concentrations are sufficient, ${ }^{[2-27,38]}$ while it is also important to have an adequate time-period between the drug and radiation, ${ }^{[8,9,39]}$ since the active metabolite, $\mathrm{dFdCTP}$, is retained for at least $24 \mathrm{~h}$ in tumors this will allow to maintain sufficiently high levels. ${ }^{[19]}$ This delay will also prevent cumulative toxicity. In addition to the radiosensitizing effect of gemcitabine, also its main catabolite, difluorodeoxyuridine, has been shown to be a good radiosensitizer ${ }^{[40,41]}$ while the catabolite is maintained at micromolar levels for days, including brain. This catabolite was recently shown to be able to inhibit thymidylate synthase. ${ }^{[42]}$ This inhibition, leading to an accumulation of deoxyuridine triphosphate (dUTP), might be basis for an additional radiosensitizing effect. ${ }^{[9]}$ Hence a dual radiosensitization might be achieved in glioma.

In conclusion, this study shows that fixed dose rate infusion of gemcitabine given before radiotherapy is clinically effective as a radiosensitizer for newly diagnosed GBM. Gemcitabine has a better cost effectiveness compared to the financial cost temozolomide. Further investigation of chemo-radiotherapy is needed and a Phase 3 trial with a higher number of patients will be initiated, to determine whether the gemcitabine radiosensitizing effect can be achieved irrespective of the methylation status of the MGMT promoter. ${ }^{[30]}$

\section{Financial support and sponsorship}

This study was supported and coordinated by the Egyptian ministry of higher education grant, Egypt.

\section{Conflicts of interest}

There are no conflicts of interest.

\section{REFERENCES}

1. Laperriere N, Perry J, Zuraw L; Neuro-oncology Disease Site Group. Radiotherapy for newly diagnosed malignant glioma in adults. Toronto (ON): Cancer Care Ontario; 2005 Nov 2 [In review 2011 Sep]. Program in Evidence-based Care Evidence-based Series No.: 9-3.

2. Stupp R, Mason WP, van den Bent MJ, Weller M, Fisher B, Taphoorn MJ, Belanger K, Brandes AA, Marosi C, Bogdahn U, Curschmann J, Janzer RC, Ludwin SK, Gorlia T, Allgeier A, Lacombe D, Cairncross JG, Eisenhauer E, Mirimanoff RO; European Organisation for Research and Treatment of Cancer Brain Tumor and Radiotherapy Groups; National Cancer Institute of Canada Clinical Trials Group. Radiotherapy plus concomitant and adjuvant temozolomide for glioblastoma. N Engl J Med 2005;352:987-96.

3. Stupp R, Hegi ME, Mason WP, van den Bent MJ, Taphoorn MJ, Janzer RC, Ludwin SK, Allgeier A, Fisher B, Belanger K, Hau P, Brandes AA, Gijtenbeek J, Marosi C, Vecht CJ, Mokhtari K, Wesseling P, Villa S, Eisenhauer E, Gorlia T, Weller M, Lacombe D, Cairncross JG, Mirimanoff RO; European Organisation for Research and Treatment of Cancer Brain Tumour and Radiation Oncology Groups; National Cancer Institute of Canada Clinical Trials Group. Effects of radiotherapy with concomitant and adjuvant temozolomide versus radiotherapy alone on survival in glioblastoma in a randomised phase III study: 5-year analysis of the EORTCNCIC trial. Lancet Oncol 2009;10:459-66.

4. Philip-Ephraim EE, Eyong KI, Williams UE, Ephraim RP. The role of radiotherapy and chemotherapy in the treatment of primary adult high grade gliomas: assessment of patients for these treatment approaches and the common immediate side effects. ISRN Oncol 2012;2012:902178.

5. Mathieu D, Fortin D. The role of chemotherapy in the treatment of malignant astrocytomas. Can J Neurol Sci 2006;33:127-40.

6. Hegi ME, Diserens AC, Gorlia T, Hamou MF, de Tribolet N, Weller M, Kros JM, Hainfellner JA, Mason W, Mariani L, Bromberg JE, 
Hau P, Mirimanoff RO, Cairncross JG, Janzer RC, Stupp R. MGMT gene silencing and benefit from temozolomide in glioblastoma. $N$ Engl J Med 2005;352:997-1003.

7. van Nifterik KA, van den Berg J, Stalpers LJ, Lafleur MV, Leenstra S, Slotman BJ, Hulsebos TJ, Sminia P. Differential radiosensitizing potential of temozolomide in MGMT promoter methylated glioblastoma multiforme cell lines. Int J Radiat Oncol Biol Phys 2007;69:1246-53.

8. Shewach DS, Lawrence TS. Gemcitabine and radiosensitization in human tumor cells. Invest New Drugs 1996;14:257-63.

9. Shewach DS, Lawrence TS. Nucleoside radiosensitizers. In: Cancer drug discovery and development entitled Deoxynucleoside analogues in cancer therapy, edited by GJ Peters, Humana press, 2006, p. 289-330 [chapter 13].

10. Shewach DS, Lawrence TS. Antimetabolite radiosensitizers. J Clin Oncol 2007;25:4043-50.

11. Pastor-Anglada M, Cano-Soldado P, Errasti-Murugarren E, Casado FJ. SLC28 genes and concentrative nucleoside transporter (CNT) proteins. Xenobiotica 2008;38:972-94.

12. Heinemann V, Hertel LW, Grindey GB, Plunkett W. Comparison of the cellular pharmacokinetics and toxicity of 2',2'-difluorodeoxycytidine and 1-beta-D-arabinofuranosylcytosine. Cancer Res 1988;48:402431 .

13. Bergman AM, Pinedo HM, Peters GJ. Determinants of resistance to 2',2'-difluorodeoxycytidine (gemcitabine). Drug Resist Updat 2002;5:19-33.

14. Mini E, Nobili S, Caciagli B, Landini I, Mazzei T. Cellular pharmacology of gemcitabine. Ann Oncol 2006;17 Suppl 5:v7-12.

15. Elnaggar M, Giovannetti E, Peters GJ. Molecular targets of gemcitabine action: rationale for development of novel drugs and drug combinations. Curr Pharm Des 2012;18:2811-29.

16. Tempero M, Plunkett W, Ruiz Van Haperen V, Hainsworth J, Hochster H, Lenzi R, Abbruzzese J. Randomized phase II comparison of dose-intense gemcitabine: thirty-minute infusion and fixed dose rate infusion in patients with pancreatic adenocarcinoma. $J$ Clin Oncol 2003;21:3402-8.

17. Peters GJ, Clavel M, Noordhuis P, Geyssen GJ, Laan AC, Guastalla J, Edzes HT, Vermorken JB. Clinical phase I and pharmacology study of gemcitabine (2', 2'-difluorodeoxycytidine) administered in a two-weekly schedule. J Chemother 2007;19:212-21.

18. Vernejoul F, Ghénassia L, Souque A, Lulka H, Drocourt D, Cordelier P, Pradayrol L, Pyronnet S, Buscail L, Tiraby G. Gene therapy based on gemcitabine chemosensitization suppresses pancreatic tumor growth. Mol Ther 2006;14:758-67.

19. Ruiz van Haperen VW, Veerman G, Boven E, Noordhuis P, Vermorken JB, Peters GJ. Schedule dependence of sensitivity to 2',2'-difluorodeoxycytidine (Gemcitabine) in relation to accumulation and retention of its triphosphate in solid tumour cell lines and solid tumours. Biochem Pharmacol 1994;48:1327-39.

20. Veerman G, Ruiz van Haperen VWT, Vermorken JB, Noordhuis P, Braakhuis BJM, Pinedo HM, Peters GJ. Antitumor activity of prolonged as compared with bolus administration of 2',2'-difluorodeoxycytidine in vivo against murine colon tumors. Cancer Chemother Pharmacol 1996;38:335-42.

21. Abbruzzese JL. New applications of gemcitabine and future directions in the management of pancreatic cancer. Cancer 2002;95:941-5

22. Poplin E, Feng Y, Berlin J, Rothenberg ML, Hochster H, Mitchell E, Alberts S, O’Dwyer P, Haller D, Catalano P, Cella D, Benson AB 3rd. Phase III, randomized study of gemcitabine and oxaliplatin versus gemcitabine (fixed-dose rate infusion) compared with gemcitabine (30-minute infusion) in patients with pancreatic carcinoma E6201: a trial of the Eastern Cooperative Oncology Group. J Clin Oncol
2009;27:3778-85

23. Gertler SZ, MacDonald D, Goodyear M, Forsyth P, Stewart DJ, Belanger K, Perry J, Fulton D, Steward W, Wainman N, Seymour L. NCIC-CTG phase II study of gemcitabine in patients with malignant glioma. (IND.94). Ann Oncol 2000;11:315-8.

24. Weller M, Streffer J, Wick W, Kortmann RD, Heiss E, Küker W, Meyermann R, Dichgans J, Bamberg M. Preirradiation gemcitabine chemotherapy for newly diagnosed glioblastoma. A phase II study. Cancer 2001;91:423-7.

25. Ostruszka LJ, Shewach DS. The role of cell cycle progression in radiosensitization by 2',2'-difluoro-2'-deoxycytidine. Cancer Res 2000;60:6080-8.

26. Genç M, Castro Kreder N, Barten-van Rijbroek A, Stalpers LJ, Haveman J. Enhancement of effects of irradiation by gemcitabine in a glioblastoma cell line and cell line spheroids. J Cancer Res Clin Oncol 2004;130:45-51.

27. Fehlauer F, Muench M, Smid EJ, Slotman B, Richter E, Van der Valk P, Sminia P. Combined modality therapy of gemcitabine and irradiation on human glioma spheroids derived from cell lines and biopsy tissue. Oncol Rep 2006;15:97-105.

28. Galbán S, Lemasson B, Williams TM, Li F, Heist KA, Johnson TD, Leopold JS, Chenevert TL, Lawrence TS, Rehemtulla A, Mikkelsen T, Holland EC, Galbán CJ, Ross BD. DW-MRI as a biomarker to compare therapeutic outcomes in radiotherapy regimens incorporating temozolomide or gemcitabine in glioblastoma. PLoS One 2012; 7:e35857.

29. Sigmond J, Honeywell RJ, Postma TJ, Dirven CM, de Lange SM, van der Born K, Laan AC, Baayen JC, Van Groeningen CJ, Bergman AM, Giaccone G, Peters GJ. Gemcitabine uptake in glioblastoma multiforme: potential as a radiosensitizer. Ann Oncol 2009;20:1827.

30. Metro G, Fabi A, Mirri MA, Vidiri A, Pace A, Carosi M, Russillo M, Maschio M, Giannarelli D, Pellegrini D, Pompili A, Cognetti F, Carapella CM. Phase II study of fixed dose rate gemcitabine as radiosensitizer for newly diagnosed glioblastoma multiforme. Cancer Chemother Pharmacol 2010;65:391-7.

31. Kim MM, Schipper M, Cao Y, Junck L, Marnmoser A, Heth J, Sagher O, Lawrence TS, Tsien C. A phase I dose-escalation study of gemcitabine plus standard radiation therapy for malignant high grade gliomas. Int J Radiat Oncol Biol Phys 2014;90:S282.

32. Common Terminology Criteria for Adverse Events v3.0 (CTCAE). Available at: http://ctep.cancer.gov (Last Accessed 1 July 2009).

33. Macdonald DR, Cascino TL, Schold SC Jr, Cairncross JG. Response criteria for phase II studies of supratentorial malignant glioma. $J$ Clin Oncol 1990;8:1277-80.

34. Beauchesne PD, Taillandier L, Bernier V, Carnin C. Concurrent radiotherapy: fotemustine combination for newly diagnosed malignant glioma patients, a phase II study. Cancer Chemother Pharmacol 2009;64:171-5.

35. Athanassiou H, Synodinou M, Maragoudakis E, Paraskevaidis M, Verigos C, Misailidou D, Antonadou D, Saris G, Beroukas K, Karageorgis P. Randomized phase II study of temozolomide and radiotherapy compared with radiotherapy alone in newly diagnosed glioblastoma multiforme. J Clin Oncol 2005;23:2372-7.

36. Rekers NH, Sminia P, Peters GJ. Towards tailored therapy of glioblastoma multiforme. J Chemother 2011;23:187-99.

37. Peters GJ, Veerkamp JH. Pyrimidine metabolism in rat brain cortex and liver. Adv Exp Med Biol 1984;165:531-4.

38. van Putten JWG, Groen HJM, Smid K, Peters GJ, Kampinga $\mathrm{HH}$. End-joining deficiency and radiosensitization induced by gemcitabine. Cancer Res 2001;61:1585-91.

39. Pauwels B, Korst AE, Lardon F, Vermorken JB. Combined modality therapy of gemcitabine and radiation. Oncologist 2005;10:34-51. 
40. Pauwels B, Korst AE, Lambrechts HA, Pattyn GG, de Pooter CM, Lardon F, Vermorken JB. The radiosensitising effect of difluorodeoxyuridine, a metabolite of gemcitabine, in vitro. Cancer Chemother Pharmacol 2006;58:219-28.

41. Wouters A, Pauwels B, Burrows N, Baay M, Deschoolmeester V, Vu TN, Laukens K, Meijnders P, Van Gestel D, Williams KJ, Van den Weyngaert D, Vermorken JB, Pauwels P, Peeters M, Lardon F. The radiosensitising effect of gemcitabine and its main metabolite $\mathrm{dFdU}$ under low oxygen conditions is in vitro not dependent on functional HIF-1 protein. BMC Cancer 2014;14:594.

42. Honeywell RJ, Ruiz van Haperen VW, Veerman G, Smid K, Peters GJ. Inhibition of thymidylate synthase by $2^{\prime}, 2^{\prime}$-difluoro-2'deoxycytidine (Gemcitabine) and its metabolite 2',2'-difluoro-2'deoxyuridine. Int J Biochem Cell Biol 2015;60:73-81. 